\title{
Governing the School by Transnational Networks: The OECD PISA Policy Advisor Network in the Global Field of Power.
}

\author{
Oliver Wieczorek ${ }^{1}$, Richard Münch ${ }^{1,2}$, Alexander Brand ${ }^{1}$ and Silvia Schwanhäuser ${ }^{3}$ \\ ${ }^{1}$ University of Bamberg \\ ${ }^{2}$ Zeppelin University Friedrichshafen \\ ${ }^{3}$ Institute for Employment Research
}

\begin{abstract}
The OECD is one of the key players in global education policy advice, informing education governance reforms around the globe with the PISA test. At the same time, it is part of the edu-business network comprised of companies, philanthropies, consulting agencies and think tanks profiting from educational governance reforms and large-scale testing. In order to exert influence on national educational reforms, different types of complementary expertise and collaborations between different types of actors must be coordinated. To analyze this form of collaboration between different actors and to map the global edu-business and global policy advisor networks having emerged around the OECD's PISA-tests, we make use of a combination of Habitus-Field Theory and Social Network Theory. We introduce the concepts of boundary-spanning actors and fieldtranscending social capital and apply our concepts to a two-level network analysis to investigate the embeddedness of the OECD in different social fields and the global field of power. The first layer is based on official collaborations among organizational actors situated in different sectors of the field of power. The second layer comprises of individual collaborations such as scientific cooperation, board interlocks and multiple affiliations. Furthermore, we look at network closure and density to investigate the exclusion of competing actors from taking part in the global edu-business. Our findings indicate that the OECD draws on experts and actors located in different fields to exert influence on national educational reforms. Finally, the global network of policy advisors is able to coordinate the different forms of expertise by installing a system of patronage, consisting of a small number of key players and large numbers of organizations and individuals that are needed to set education reforms in motion but are excluded from the core of the collaboration network.
\end{abstract}

Keywords: OECD; PISA; Global Field of Power; Global Edu-Business; Field-Transgressing Social Capital; Interfield-Relations, Habitus-Field Theory, Social Network Analysis

Word Count: 8988

\section{Introduction}

Education is considered a growing, global market with promising revenues (Ball 2012; Hogan, Sellar, and Lingard 2015; Lingard 2013). McKinsey expects education to become a \$8 trillion market worldwide in 2020 (McKinsey/GSMA 2012: 5). The company recommends investing in this global edu-business associated with educational testing and the provision of 
evidence for national educational reforms. Governments, in turn, implement the provided centralized and transnational testing as quality assurance of education and use it as leverage for educational reforms (Addey 2017; Niemann and Martens 2018; Rautalin, Alasuutari, and Vento 2019; Wilkins et al. 2019).

The need for producing evidence in transnational tests as leverage for educational reforms and for quality-assurance of education creates an economically profitable market for the many different actors of the global edu-business including textbook publishers, the testing industry, educational researchers, educational economists, NGOs, think tanks, investors and reformers. These actors are further backed by missionary philanthropic foundations aiming at creating a better world. They are heavily involved in this business through funding educational reform projects with generous grants (Hogan 2015; Lewis 2017). The Organization for Economic Cooperation and Development's (OECD) PISA-test is central within this transnational network and thus one of the main sources of revenue in this global edu-business, as more and more countries participate in the test (Engel and Frizzell 2015). Their number has continued to rise ever since 2000, when the OECD started to carry out the Programme for International Student Assessment (PISA) as an international three-yearly performance comparison of fifteen-year-old pupils in their basic reading comprehension, mathematics and science skills. Around the OECD and the PISA-test emerged a huge, collaborative network, which is most powerful in advancing school reform according to programs considered "best practice" worldwide (e.g. Ball 2016).

This form of educational governance championed by the OECD replaces governance by means of legislation on the basis of parliamentary majorities by democratically not legitimized transnational expert-networks including, among others, Pearson, the Hoover Institution or McKinsey (Lewis and Hogan 2019). These networks exert an influence on parliaments and political parties while pushing teacher associations into the background by means of so-called soft instruments in the form of statistical figures, monitoring and benchmarking. These experts are trusted insofar as their judgements are founded on scientifically sound knowledge, thus enabling their expertise to be included into informed policy-making (Head 2016; Lewis and Lingard 2015).

The impact of PISA and the global policy advisors network on national education reforms enhances the growing intersection between the globalized edu-business, the testing industry and governments. In this world where educational experts use the PISA-tests to engage in the 
the production, interpretation and application of data, actors involved in this process are most powerful and have the ability to shape educational reforms by linking their expertise (Addey and Sellar 2018; Hartong 2016; Hartong 2018a; Lingard, Martino, and Rezai-Rashti 2013; Sellar 2015).

Against this backdrop, we scrutinize the structure of the global policy advisor network that has emerged around the OECD and PISA and coordinates expertise on education on the global level to guide educational reforms on the national level (Ball 2012, 93-145; Hogan 2015; Hogan 2016; Sellar and Lingard 2013). To do so, we aim to...

1) ... provide a theoretical and methodological framework to map the interrelation of different types of actors of the global edu-business and policy advisor network that has emerged around the OECD’s PISA test.

2) ... understand and explain the role of different actors related to the OECD's PISA test as prerequisite for steering national education reforms.

In order to achieve these two aims and to provide novel insights, we apply a theoretical framework based on Habitus-Field Theory and Social Network Theory to map the global policy advisor network and to see how its domain-spanning structure is shaped and use techniques of Social Network Analysis to uncover the field-crossing structures that are preconditions for the OECD to steer national education policy.

\section{Habitus Field Theory: The edu-business and policy advisor network in the global field of power}

The OECD is part of a global policy-advisor network and the global edu-business. It is tightly connected to consulting agencies, philanthropy, think tanks, testing industry, scholars and governmental units. These specialized actors share the same common aims regarding educational governance such as, for instance, the improvement of educational outcomes by implementing evaluation regimes and by establishing educational benchmarking and competition in as many countries as possible (Hartong 2016; Leuze, Martens, and Rusconi 2007; Lewis and Hardy 2015; Lewis 2017). To do so, they collaborate on multiple levels, even if different types of actors follow different institutional logics.

In Habitus-Field Theory, actors such as the OECD, Pearson or McKinsey take positions in the global field of power. The global field of power can be conceived as a sector of the social space, where actors compete for the opportunity to shape world-views and the exchange rates 
of different sorts of capital (Bourdieu 1996; Bourdieu, Loic J. D. Wacquant, and Farage 1994; Schmitz, Witte, and Gengnagel 2017). The global field of power is comprised of an interrelated objective structure (distribution of economic, social, cultural and symbolic capital and power) and subjective structure (interpretation of the logics and shared world-views) (Bourdieu 1985, 1998). A definition of all fields reviewed in our study is provided in appendix A.

A field's subjective structure comprises the illusio, nomos, doxa, libido and habitus. Taken together, these govern the praxis of the field. The illusio includes the belief in the importance of the competition prevailing in a field (e.g. to generate knowledge in academia). Nomos comprises the principles of vision and division in a field. These contain the rules of who is entitled to take part in the field, where the field ends in the social space, how the field is internally divided and who represents the field in question. Doxa is defined as the shared and unquestioned beliefs on what is at stake in a given field, how to properly compete for what is at stake and how to distribute capital rightfully (Bourdieu 1989, 18; Bourdieu 2000, 143f.; Bourdieu and Wacquant 1992, 25f.). These three concepts are connected to the libido - or “objects of desire” - present in the field (Schmitz, Witte, and Gengnagel 2017, 55).

To link a field's objective and subjective structures, actors must have the capacity to intuitively navigate through the field, that is they need to establish how to invest capital to maximize capital accumulation and to maximize the impact on the illusio (= practical sense). To do so, every actor in a given field must acquire a field-specific form of habitus. Habitus is understood as a set of dispositions that defines aims, strategies taken by actors, and their "'sense of one's place' but also a 'sense of the place of others"” within the field (Bourdieu 1985, 734).

Translated to the global policy advisor network, the OECD and other actors strive to guide national education policy and educational assessments (illusio, doxa, and libido). Their habitus comprises of views on necessities of educational reforms, including who is subject to assessments, and how to conduct these assessments and to compare countries the right way (practical sense). If actors do not match these criteria, they are either excluded from the global policy advisor network or accumulate less capital and are not worthy of representing the global policy advisor network (nomos). Following this line of reasoning, the OECD must be backed by a large stable network of influential and capital-rich actors located in different fields. 


\section{Social Network Theory: Advisor Networks across a Variety of Fields}

In order to conceptualize the urge for collaboration and the need of the OECD to rally actors located in different fields within the field of power, we need concepts that enable us to bridge the concepts inherent in the Habitus. We therefore have to supplement the perspective provided by Habitus-Field Theory with concepts provided by Network Theory.

We do so using concepts stemming from Social Network Theory, since both share central assumptions. Firstly, the conceptual foundation of both theories is relationality. For networks, this assumption implies that actors, local structures and the overall structures of the network influence each other (Barabási et al. 2002; Kossinets and Watts 2006; Watts 1999). The same holds true for Habitus-Field Theory, as the objective and subjective structures of fields as well as the habitus are interrelated.

Secondly, both theories share the assumption that relations among actors are culturally embedded (Fuhse 2009; Pachucki and Breiger 2010; Serre and Wagner 2015; White et al. 2004). We interpret cultural embeddedness as referring to the figuration of fields, their links among each other and their relations to the field of power. Besides their relative interconnectedness, their cultural embeddedness impacts the autonomy of fields (Krause 2018). Thus, the mixture of cultural embeddedness and interrelatedness of relatively autonomous fields shape the opportunities for collaboration or competition within and between fields.

As both theories provide concepts for analyzing the impact of groups, networked relations and interactions among actors on structure, we take social capital as the main link between the two theories. Since network theory puts an emphasis on manifest interaction instead of latent structures derived from an underlying field-structure, different dimensions of social capital can be identified to expand the notion of social capital provided by Habitus-Field Theory (Borgatti and Everett 2006; Burt 2000; Lin 2017). Boundary-spanning actors and fieldcrossing social capital

Taking our conceptualization one step further, we have to assume that actors have the ability to take part in different fields at the same time. Actors do so, since the global field of power is composed of different fields. These actors must aim to exploit collaborations to gain access to other fields and the capital included. 
Based on this assumption and the fact that different types of actors of the edu-business are present in the the global policy advisor network, the OECD and its collaborators (such as Pearson or the Hoover Institution) possess different forms of symbolic capital. These forms comprise the symbolic value of expertise in consulting, scientific, political and bureaucratic capital. However, since these actors are situated within the field of power, and the field of power covers different fields, the forms of symbolic capital might also be directed to other fields in order to establish collaborations and to exert influence. Additionally, these actors possess huge volumes of economic capital, social capital (collaborations between the OECD, Pearson, McKinsey etc.) and cultural capital (knowledge on educational governance and educational research). Such capital volumes enable the OECD to establish collaborations among different types of actors revolving around PISA and to steer education reforms on the national level. Therefore, we propose to conceive of the OECD and other actors with the ability and type of symbolic capital enabling them to intrude into other fields as boundaryspanning actors (see f.e. Aldrich and Herker 1977; Williams 2011; Williams 2013).

We must therefore assume that the position of boundary-spanning actors OECD and other organizations of the global edu-business is delicate insofar as they need to have the ability to coordinate different types of symbolic capital. Applied to our case, the OECD aims to be acknowledged as the single most important actor for education assessment and provider of educational evidence by national governments. To this end, the OECD relies on modes of professional consultation, provided by think tanks, consulting agencies, philanthropies and educational scientists in order to impact the agency of governments (Lingard 2013; SchmidtWellenburg 2017; Schinkel and Noordegraaf 2011). The OECD strengthens its ability to coordinate, to relate and translate different forms of habitus, symbolic capital and cultural capital by drawing on different experts and by tying the different forms of expertise together. Furthermore, boundary-spanning actors must be able to generate a specific form of social capital which facilitates the coordination of actors and the expertise related to different illusios, doxa, libidos and habitus. The possibility to accumulate and relate different forms of capital, to translate different forms of habitus, and have access to collaborating groups of actors located in different fields is defined as field-crossing social capital.

In this regard, we propose three dimensions of field-crossing social capital to capture the ability of boundary-spanning actors to link and to relate different forms of expertise in addititon to the possibility to establish collaboration among fields. 
The first dimension of field-crossing social capital is linked to the direct accessability of expertise present in the global policy network and related governmental bodies. Professional expertise is used by governmental bodies to legitimize decisions and educational reforms as suggested by Schmidt-Wellenburg (2017). In our case, field-crossing social capital is associated with the opportunity to centralize the flow of expertise necessary to steer educational reforms. We therefore propose:

1) The amount of field-crossing social capital is associated with the access to expertise provided by actors in different fields, which can be utilized to exert influence on the subjective structure of fields in question.

The second dimension concerns the ability to transform different sorts of capital between individuals and organizations. Here, Habitus-Field Theory provides us with the concepts of delegation and representation which enable us to assume that field-crossing social capital is transferable between individuals and organizations (Bourdieu and Robinson 1985; Bourdieu 1986). Being able to transfer sorts of capital between individuals and organizations (e.g. Andreas Schleicher as the director of the OECD) implies the capability to generate fieldcrossing social capital on many levels at the same time and to turn individual collaborations into strategic partnerships (officialization).

From the perspective of Social Network Analysis, the ability to establish and secure relations on multiple layers is coined "multiplexity” (Kim and Goh 2013). In Social Network Analysis, multiplexity is scrutinized for the investigation of different layers of cooperation (Lazega and Pattison 1999), or the accumulation of power and influence (Padgett and Ansell 1993; Padgett and McLean 2006). In line withthe possibility to transfer social capital from the individual to the organizational level and vice versa, and the need to gain access to and translate different types of symbolic capital, we propose two types of collaboration linking multiplexity to fieldcrossing social capital.

First, personal linkages spanning organizational boundaries, which bear the potential to transfer individually accumulated capital, add to the OECD's chances to impact national education reforms. As seen in studies conducted by Burt (1980) and Pusser et. al. (2006) on board-interlocks, such officialized connections make it possible to exert influence on other organizational actors. In our case, organizations of the global policy advisor network are 
situated in different fields. And have boards of directors and expert commissions.Individuals serving on more than one organization have the ability to take positions in multiple fields at the same time. This, in turn, makes relations spanned by board memberships, or at least being recruited as an expert by multiple organizations at the same time, options for field-crossing social capital. These individual actors have the ability to incorporate cultural and symbolic capital required in different fields in addition to different doxa, nomoi and illusios present in their habitus. By doing so, these actors acquire the ability to act as mediators between different fields, and to centralize the expertise nessecary to steer educational reforms.

Secondly, officialized collaborations between the OECD, government agencies, policyadvisors and consulting agencies on the organizational level increase the legitimation of guiding educational reforms on the national level.Officialized collaborations signal reciprocal acknowledgement and enable the partaking actors to share expertise (also of third-parties) faster and more effectively. By doing so, they are able to generate a higher rate of return on capital investments. Furthermore, officialized collaborations signal a convergence of beliefs (see Grow, Flache, and Wittek 2017) and aims (practice and habitus). Along this line, we propose that the ability to initiate collaboration between fields on different layers and the ability to transfer various sorts of capital between those layers account for interdependencies among collaborating actors located in different fields; the capability to officialize and relate different forms of expertise; and the opportunity of the global policy advisor network to steer national educational reforms by having access to different fields. In line with the three forms of collaboration, we assume:

2) The more layers collaborations between actors in different fields can take and the better the chances to transfer capital accumulated within these layers, the more field-crossing social capital an actor in question will have at his disposal.

The third dimension of field-crossing social capital is associated with the network closure of boundary-spanning actors. With regard to Social Network Theory, we notice that not every relation or collaboration is created on equal terms. Instead, we suppose field-crossing social capital to depend on the differences in capital volumes of actors and their chances to influence their collaboration partners; and on their chances to transcend the borders of their fields while preventing others from doing so. Habitus-Field Theory emphasizes that actors possessing high volumes of capital are more likely to have an impact on the subjective structure of their field 
(Bourdieu 2000, 71). If these dominant actors collaborate and span the boundaries of their respective fields, the resulting collaborations enable the participating actors to form fieldcrossing networks. These networks can be used to gain access and to exert some influence on other fields via their collaborators.

Since boundary-spanning actors may or may not be similarly endowed with different forms of capital, two different types of collaboration between fields emerge as a foundation for fieldcrossing social capital. These forms differ accordingly in the ability to exert power on collaborators.

The first type considers field-crossing social capital to be generated by alliances between powerful actors situated in different fields. These alliances are characterized by powersymmetries and aim to improve chances of capital accumulation within respective fields by mobilizing the expertise and legitimation provided by actors from other fields. We postulate that the establishment of power-symmetrical collaborations and the accumulation of fieldcrossing social capital lead to an alignment of fields, if boundary-spanning actors successfully relate subjective structures and different forms of symbolic capital in each field.

If this assumption applies, a division of labor emerges by drawing on trust in expertise. Expertise is amassed in the respective organizations and helps to legitimize strategies of the actors to gain influence in the respective fields (Schinkel and Noordegraaf 2011; SchmidtWellenburg 2017). By doing so, actors may become dependent on each other, but are nevertheless able to maximize the accumulation rate of the different sorts of capital within their fields by specialization and division of labor; and the capability to draw on different forms of expertise and aid provided by collaborators.

The second type considers field-crossing social capital to be generated by a system of patronage between more powerful actors (e.g. OECD) and less powerful actors with a limited ability to span the borders of different fields. These alliances are characterized by an imbalance of power. Powerful boundary-spanning actors have the ability to shape the relations in other fields in such a way that their less powerful collaborators become dominant within their fields. Being partners, they transfer different forms of capital to their less powerful allies, while both are changing the illusio and exchange rates of capitals in the fields in question. If these collaborators succeed, the "patrons” (e.g. the OECD) obtain increasing 
rates of return on field-specific capital investment, besides being acknowledged for actively participation in a given field-specific competition.

Following this line of reasoning, we assume that the possession of field-crossing social capital tied to symmetrical power relations as well as systems of patronage increases the chances of networks or clusters of boundary-spanning actors to impose subjective structures of their field effectively on other fields. Applied to our case, the global network of policy advisors improves its chances to guide educational reforms by drawing on PISA and shared views on education. We therefore assume the following for the third dimension of field-crossing social capital:

3) The denser the collaboration between actors located in different fields, the greater the impact of boundary-spanning actors on the subjective structures of other fields, the stronger the system of patronage and the higher the rate of returns and legitimation, the more fieldcrossing social capital an actor will have at his disposal.

\section{Operationalization of Field-Crossing Social Capital}

The three dimensions of field-crossing social capital introduced in the previous section can be operationalized using canonical measures of centrality, transitivity and density present in social network analysis.

In Social Network analysis, Centrality-measures are the most prevalent indicators of social capital. In total, there are four canonical centrality-measures: Degree Centrality, Eigenvector Centrality, Betweenness Centrality and Closeness Centrality (Freeman 1977). Degree Centrality is defined as the total number of direct connections to neighboring actors. Weighted degree is defined as a combination of degree and relative strength of the direct connections between actors and their neighbors in the network (Opsahl, Agneessens, and Skvoretz 2010). Eigenvector Centrality is defined as the number of ties that are reached by a neighbor of a given actor (Newman 2004). Betweenness Centrality is the share of shortest paths an actor has within a given network. At last, Closeness Centrality is defined as the weighted distance between a given actor and all other actors in the network.

We postulate (weighted) Degree Centrality to be associated with the first dimension of fieldcrossing social capital. On the level of relations between fields, Degree Centrality is the number of boundary-spanning ties per actor located within different fields, whereas the 
distribution of weighted degree on the organizational level indicates how centralized the possibility of direct influence is. We expect that the greater the share of connections to actors situated in other fields, the more likely it is for an actor of the global policy advisor network to mobilize expertise and legitimation from other fields. We further expect that the more connections an actor has accumulated on different network-layers and the more these connections overlap, the better an actor is able to transfer different sorts of cultural and symbolic capital between these layers.

Eigenvector Centrality is chosen to represent the second dimension of field-crossing social capital. On the different network layers, it represents the ability to gain access to and influence on other fields to establish the system of power-symmetrical collaboration and patronage outlined in the previous section. Therefore, Eigenvector Centrality also includes the potential to reach other actors within the field of the collaborating actor (e.g. field of philanthropy $\rightarrow$ economic field $\rightarrow$ economic field) and towards actors in other fields via their collaborators (e.g. field of philanthropy $\rightarrow$ economic field $\rightarrow$ bureaucratic field).

To investigate the third dimension of field-crossing social capital even further, transitivity as indicator of network closure and thus the ability to influence the subjective structures of different fields while excluding other actors from doing so is applied. Transitivity is defined as the share of triplets (= the number of fully connected triads) of all possible but not realized triples (Newman 2006). For example, we may speak of a triplet, if the OECD collaborates with Pearson, Pearson with the US-Government, and further OECD partners with the USGovernment. By applying transitivity, we obtain a picture of the chances of the OECD and other actors of the global policy advisor network to develop a shared view on education, and how to steer educational reforms drawing on PISA tests (Ball 2012; Lewis 2017; Mahon 2010; Meyer 2014).

\section{Data and methods}

To apply the theoretical considerations and derived concepts of boundary-spanning actors and field-crossing social capital on the global policy advisor network established around PISA, we constructed a two-layer network of the OECD and its collaboration on the organizational and the individual level. We did so to examine the official collaborations among organizations in the global policy advisor network and the individual collaborations which take place at a 
lower level and are able to circumvent possible unwelcome, official collaborations (e.g. between the OECD and test-industry companies or ministries).

Since we focus on the OECD's ability to relate different types of actors, expertise, habitus and forms of symbolic capital tied to different fields within the global field of power, we decided to analyse the OECD as a separate "field" among other fields. Therefore, the OECD as a field comprises of a single actor, differentiated into eight directorates, whereas other fields contain dozens, or even hundreds of actors. When we interpret our findings we must pay attention to avoid underestimating the centrality and importance of the OECD in the global policy advisor network.

We collected our data between 2016 and 2017 using an iterative web search. In a first step, OECD webpages and webpages of partnering organizations were searched for official collaborations. We did so by using the official OECD partners section on the webpage and reiterated this step twice on the websites of the partnering organizations. In this way, we collected data on strategical partners and the system of partronage associated with the second dimension of field-crossing social capital. This data prepared the ground for the first network layer. We then proceeded by gathering data on experts, committees and OECD directorates. Here, we utilized CVs, publication authorships of experts and co-affiliations between 2000 and 2017, spanning the first to fifth PISA test. Using CV data, we were able to collect further data on co-affiliation. We used the different types of data to construct the second network layer. Applying this iterative technique, we collected data on 1796 organizations and 4635 collaborations on the first layer along with 2231 collaborations on the second layer. In total, 6866 collaborations were established (see Appendix B for further information on the types of organizations included).

After collecting, cleaning and preparing the data, we deployed Python and the packages networkx, deepgraph and pymnet and the R igraph-package (Traxl, Boers, and Kurths 2016) to integrate the network layers and to investigate structures and distributions of field-crossing social capital.

We further introduced a ratio of field-crossing social capital between the layers and scrutinized Spearman's $\rho$ in order to compare the ability of the OECD and actors situated in different fields to amass field-crossing social capital on either the individual or the organizational level. The ratio of field-crossing social capital is calculated by dividing the number of field-crossing social capital of the first dimension found on layer 1 of the network 
(official collaboration) by the amount found on layer 2 (individual collaboration). This step enabled us to reveal different strategies to accumulate field-crossing social capital and to establish the position of field-spanning actors by using individual or officialized collaborations. To compare whether the fields and actors therein have similar chances to accumulate field spanning social capital on both layers, we calculated the Spearman's $\rho$ of the total numbers and shares of field-crossing social capital of OECD and other fields in the global field of power.

\section{Findings}

Starting with intra- and interfield connections on layer one (table 1), we see the most officialized connections by far in the economic field (1617), followed by the academic field (1297), the field of philanthropy (468), the bureaucratic field (393), professional field (332) and the field of consulting (277). Additionally, there are fields including the OECD with only a small number of official collaborations listet on their websites. These include the cultural field (122), the political field (70), the educational field (29), the OECD (13 connections), and the military field (7). Overall, the share of interfield collaborations ranges from $68.34 \%$ (economic field) to $100 \%$ in the case of the educational field, the OECD and the military field. Even fields with many hundreds of connections, such as the bureaucratic field or the field of philanthropy have shares of field-crossing social capital greater than 90\%. Apart from the economic field, it is only the academic field that displays a relatively low share of fieldcrossing social capital (74.40\%). At first glance, these numbers indicate that there are actors with a huge potential to collaborate with actors situated in other fields. At second glance, these numbers highlight the need to establish boundary-spanning collaboration to reach out for expertise and legitimation provided in other fields. Only actors situated in the academic field and the economic fields seem to rely more on the expertise provided by other experts from the same field than others in the global edu-business.

If we take a closer look at the connections among different fields, we see that both the academic and the economic field are central and strongly connected (472). Furthermore, strong connections exist between the economic field and the field of philantrophy (206), as well as the economic and academic field and the bureaucratic field, field of consulting and professional field. Besides the dominance of the economic and the academic fields, our data reveals a semi-peripheral structure of interfield collaboration between actors located in the bureaucratic field, field of consulting, field of philanthropy and professional field. These 
numbers indicate that actors situated in the academic and economic fields are pivotal, provide expertise and legitimation to other fields while accumulating field-crossing social capital and thus the ability to harmonize different forms of habitus and social capital tied to different fields. The strengths of inter-field collaborations are highlighted by colors in table 1.

The second layer provides further evidence for the importance of the first dimension of fieldcrossing social capital within the global policy advisor network, although the second layer (table 2) includes less than half of collaborations (2231 versus 4635). This means that individual collaboration and co-affiliation is less present than official collaboration. Furthermore, layer 2 highlights the opportunity for boundary-spanning individuals to tie different sectors of the global field of power together. This finding is even more remarkable, since actors with low numbers of official collaborations and field-crossing social capital in layer 1 seem to possess high levels of field-crossing social capital in layer 2. In this context, the OECD shows 166 collaborations, the military field 165, the cultural field 399 and the educational field 444 on this layer, which means that these fields and actors have disproportionally high amounts of field-crossing social capital on this level at their disposal. Nearly all other fields with high levels of field-crossing capital possess much lower amounts on layer 2. To highlight the collaborations among fields on both layers even further, we provide a "Supergraph” as seen in figure 1 (Liu et al. 2018).

Albeit the share of connections between different fields is still high in layer 2, it is lower in the cases of the academic field (62.22\%), educational field (69.37\%), field of consulting (86.01\%), cultural field (78.68\%) and the OECD (90.96\%) compared to layer 1 . In layer 2, most collaborations are found between the educational field and the bureaucratic field (94), the academic field and the educational field (86), the bureaucratic field and the academic field (68), the cultural field and the field of consulting, and the cultural field and the academic field (56 each). In this sense, the aforementied fields have the highest amount of field-crossing social capital at their disposal in layer 2.

Taking into account that the OECD is a single organization, it is very well connected in layer 2 and has disproportionally high levels of field-crossing social capital at its disposal. The highest amount of field-crossing social capital is embodied in the connections between the OECD and the academic field (38), educational field (36), bureaucratic field (28) and field of consulting (12). In this sense, the OECD is very well placed to utilize individual inter-field collaboration and, by doing so, to silently take part in other sectors of the global field of 
power. This is an indication of the central, though somewhat latent role of the individual collaborations of the OECD within the global policy advisor network and its ability to harmonize different forms of expertise, habitus, illusio, doxa and libido.

Figure 1: Supergraph of boundary-spanning social capital measured of layers 1 and 2.

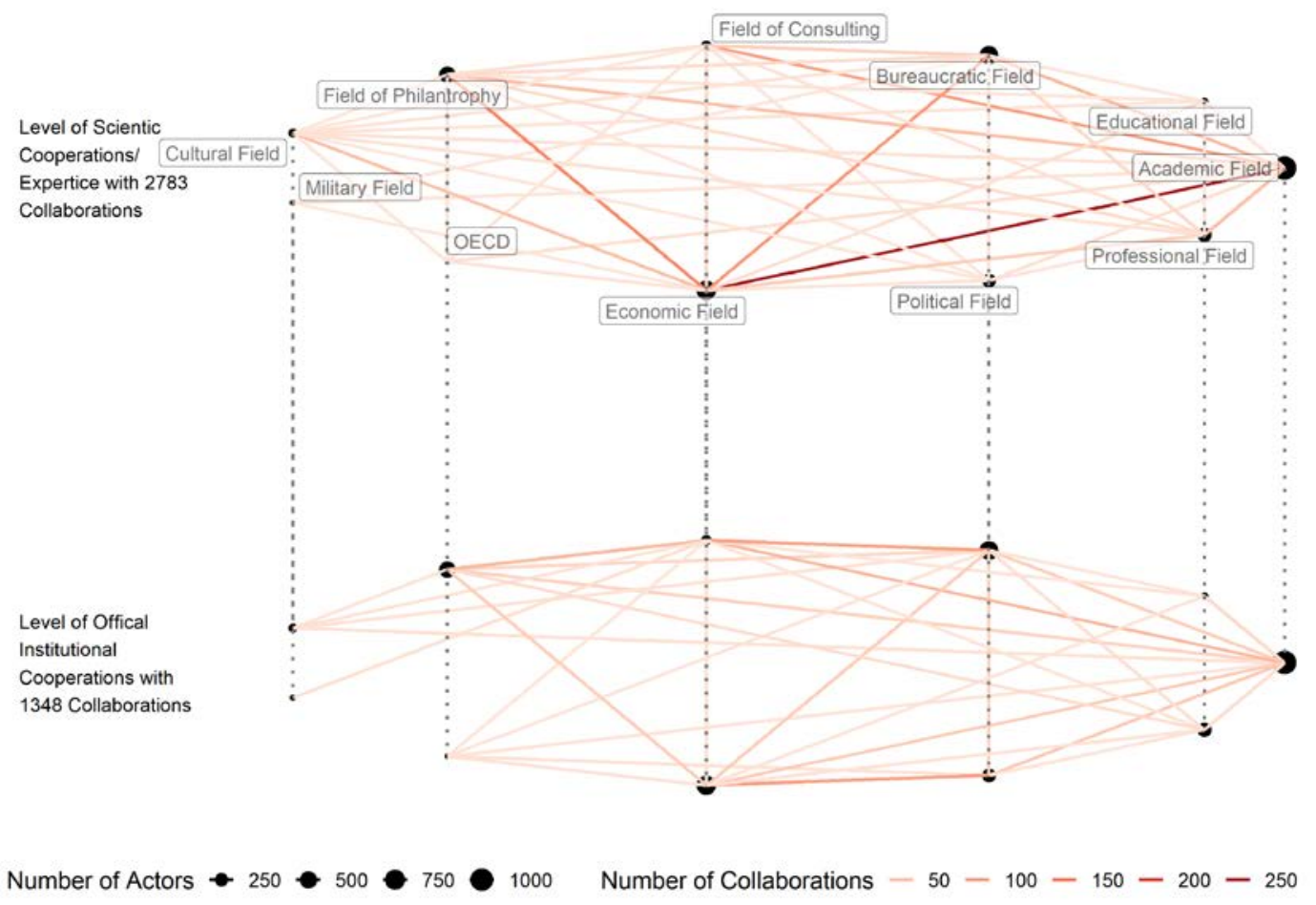


Table 1: Amount and share of field-crossing social capital measured as intra- and interfield collaborations in Layer 1.

\begin{tabular}{|c|c|c|c|c|c|c|c|c|c|c|c|c|c|}
\hline Fields & Academic & Educational & Bureaucratic & Consulting & Philantrophy & Cultural & Military & OECD & Economic & Political & Professional & $\Sigma$ & $\begin{array}{l}\% \text { share of } \\
\text { interfield- } \\
\text { connections }\end{array}$ \\
\hline Academic & 332 & 1 & 113 & 111 & 121 & 23 & 2 & 7 & 472 & 15 & 100 & 1297 & 74.40 \\
\hline Educational & 1 & 0 & 2 & 0 & 4 & 2 & 0 & 0 & 17 & 0 & 3 & 29 & 100.00 \\
\hline Bureaucratic & 113 & 2 & 16 & 29 & 36 & 10 & 1 & 0 & 141 & 11 & 34 & 393 & 95.93 \\
\hline Consulting & 111 & 0 & 29 & 7 & 36 & 3 & 0 & 2 & 61 & 1 & 27 & 277 & 97.47 \\
\hline Philantrophy & 121 & 4 & 36 & 36 & 35 & 4 & 0 & 1 & 206 & 8 & 27 & 478 & 92.68 \\
\hline Cultural & 23 & 2 & 10 & 3 & 4 & 4 & 0 & 1 & 66 & 1 & 8 & 122 & 96.72 \\
\hline Military & 2 & 0 & 1 & 0 & 0 & 0 & 0 & 0 & 4 & 0 & 0 & 7 & 100.00 \\
\hline OECD & 7 & 0 & 0 & 2 & 1 & 1 & 0 & 0 & 2 & 0 & 0 & 13 & 100.00 \\
\hline Economic & 472 & 17 & 141 & 61 & 206 & 66 & 4 & 2 & 512 & 29 & 107 & 1617 & 68.34 \\
\hline Political & 15 & 0 & 11 & 1 & 8 & 1 & 0 & 0 & 29 & 2 & 3 & 70 & 97.14 \\
\hline Professional & 100 & 3 & 34 & 27 & 27 & 8 & 0 & 0 & 107 & 3 & 23 & 332 & 93.07 \\
\hline
\end{tabular}


Table 2: Amount and share of field-crossing social capital measured as intra- and interfield collaborations in Layer 2.

\begin{tabular}{|c|c|c|c|c|c|c|c|c|c|c|c|c|c|}
\hline Field & Academic & Educational & Bureaucratic & Consulting & Philantrophy & Cultural & Military & OECD & Economic & Political & Professional & $\Sigma$ & $\begin{array}{l}\% \text { share of } \\
\text { interfield- } \\
\text { connections }\end{array}$ \\
\hline Academic & 195 & 86 & 60 & 23 & 2 & 56 & 37 & 38 & 14 & 5 & 0 & 516 & 62.21 \\
\hline Educational & 86 & 136 & 94 & 18 & 3 & 40 & 25 & 36 & 3 & 3 & 0 & 444 & 69.37 \\
\hline Bureaucratic & 60 & 94 & 8 & 54 & 1 & 32 & 0 & 31 & 1 & 6 & 7 & 294 & 97.28 \\
\hline Consulting & 23 & 18 & 54 & 27 & 0 & 56 & 0 & 12 & 0 & 3 & 0 & 193 & 86.01 \\
\hline Philantrophy & 2 & 3 & 1 & 0 & 0 & 3 & 5 & 0 & 0 & 0 & 0 & 14 & 100.00 \\
\hline Cultural & 56 & 40 & 32 & 56 & 3 & 84 & 92 & 28 & 3 & 0 & 0 & 394 & 78.68 \\
\hline Military & 37 & 25 & 0 & 0 & 5 & 92 & 0 & 6 & 0 & 0 & 0 & 165 & 100.00 \\
\hline OECD & 38 & 36 & 31 & 12 & 0 & 28 & 6 & 15 & 0 & 0 & 0 & 166 & 90.96 \\
\hline Economic & 14 & 3 & 1 & 0 & 0 & 3 & 0 & 0 & 0 & 0 & 0 & 21 & 100.00 \\
\hline Political & 5 & 3 & 6 & 3 & 0 & 0 & 0 & 0 & 0 & 0 & 0 & 17 & 100.00 \\
\hline Professional & 0 & 0 & 7 & 0 & 0 & 0 & 0 & 0 & 0 & 0 & 0 & 7 & 100.00 \\
\hline
\end{tabular}

Legend:

50 collaborations 
Table 3: Number of Actors in both layers, Rank of field-crossing social capital and ratio of capital on layer 1 and layer 2 .

\begin{tabular}{|c|c|c|c|c|c|c|}
\hline Field & 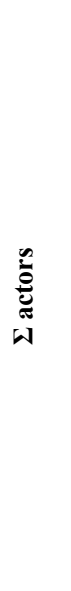 & 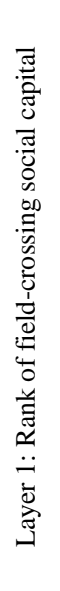 & 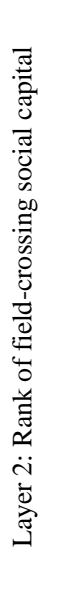 & 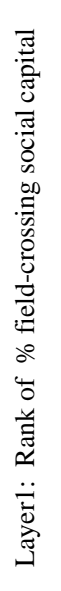 & 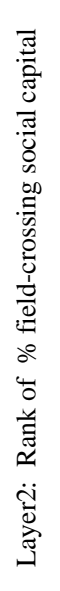 & 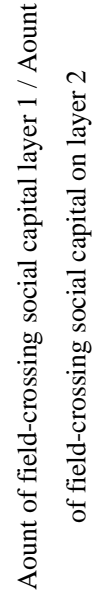 \\
\hline Academic & 552 & 2 & 1 & 10 & 11 & 0.40 \\
\hline Educational & 14 & 9 & 2 & 1 & 10 & 15.31 \\
\hline Bureaucratic & 313 & 4 & 4 & 7 & 6 & 0.75 \\
\hline Consulting & 51 & 6 & 5 & 4 & 9 & 0.70 \\
\hline Philantrophy & 205 & 3 & 10 & 9 & 1 & 0.03 \\
\hline Cultural & 29 & 7 & 3 & 6 & 8 & 3.23 \\
\hline Military & 9 & 11 & 7 & 1 & 1 & 23.57 \\
\hline OECD & 8 & 10 & 6 & 1 & 7 & 12.77 \\
\hline Economic & 338 & 1 & 8 & 11 & 1 & 0.01 \\
\hline Political & 135 & 8 & 9 & 5 & 1 & 0.24 \\
\hline Professional & 142 & 5 & 11 & 8 & 1 & 0.02 \\
\hline Total & 1786 & & & & & \\
\hline
\end{tabular}

The opportunity to mobilize official and individual collaborations as field-crossing social capital in both layers at the same time can be measured using Spearmans $\rho$ on the Ranks of field-crossing social capital in layer 1 and layer 2 and the ratio of field-crossing social capital between layer 1 and layer 2 .

Concerning Spearmans $\rho$, we see no correlation between the ranks of field-crossing social capital measured by the total number of collaborations $(\rho=-0.064, \mathrm{p}=0.85)$ and the rank of the share of collaborations per field $(\rho=-0.18, p=0.59$ ). The huge differences between the two layers in the opportunities to utilize official and individual collaborations are highlighted further by the ratio of field-crossing social capital between layer 1 and layer 2. Here, we see that the actors of the military field have staggering 23.57 times more individual than official 
collaborations; this is followed by the eduacational field with 15.31, the OECD with 12.77, and the cultural field with 3.23 times more individual than official collaborations. On the other side of the distribution, the field of philanthropy accounts for only 0.03 times the individual collaborations of official collaborations, the professional field for 0.02 times and the economic field for only 0.01 times. These findings indicate two different collaboration strategies and thus opportuinies to accumulate field-crossing social capital and position-taking as boundary-spanning actor. While actors with low ratios of collaboration on level 2 are in need of officializing their collaborations, actors with high ratios of collaborations on level 2 are aiming to establish less visible collaborations and to accumulate and relate different forms of symbolic capital inofficially.

Turning to the distribution of weighted degrees within the fields and across layers, we see highly skewed distibutions of field-crossing social capital. In layer 1, the skewness ranges from 1.32 (cultural field) to 5.92 (political field), indicating moderate to very high rightskewed distributions of field-crossing social capital. In layer two, the right-skewed distributions are more extreme. Even if there are moderately skewed distributions (cultural field, educational field and OECD with skewness of 1.38, 1.41 and 1.86 respectively) and a left skewed distribution in the case of the military field (-1.12), most distributions are extremely right skewed. Their skewness values range from 5.28 in the field of consulting up to 15.43 in the bureaucratic field, providing further evidence for the concentration of fieldcrossing social capital in the hands of only a few key actors in the global policy advisor network.

Taken together, these findings suggest a concentration of field-crossing social capital on a limited number of actors in the first dimension proposed, but also the power to translate between different forms of habitus and to relate different forms of expertise efficiently. Both layers provide evidence that many actors of the global policy advisor network are boundaryspanning actors, whereas there are central platforms for the harmonization of habitus, illusio to the belief on how to shape educational policy efficiently and the means necessary for doing so. 
Table 4: Distributions of Weighted Degree Centrality by field, layer 1.

\begin{tabular}{lcccccccc}
\hline & Field & $\mathrm{n}$ & min & mean & median & ninety & max & skew \\
\hline 1 & Academic & 552 & 0 & 12.34 & 0 & 34.00 & 222 & 3.83 \\
2 & Educational & 14 & 0 & 9.36 & 0 & 31.30 & 72 & 1.97 \\
3 & Bureaucratic & 313 & 0 & 4.44 & 0 & 19.60 & 72 & 3.30 \\
4 & Consulting & 51 & 0 & 17.14 & 0 & 52.00 & 160 & 2.59 \\
5 & Philantrophy & 205 & 0 & 8.59 & 0 & 38.00 & 76 & 2.25 \\
6 & Cultural & 29 & 0 & 19.10 & 0 & 62.40 & 108 & 1.32 \\
7 & Military & 9 & 0 & 2.67 & 0 & 4.80 & 24 & 2.07 \\
8 & OECD & 8 & 0 & 10.50 & 0 & 25.20 & 84 & 1.86 \\
9 & Economic & 338 & 0 & 22.99 & 0 & 60.00 & 458 & 5.62 \\
10 & Political & 135 & 0 & 1.56 & 0 & 0.00 & 60 & 5.92 \\
11 & Professional & 142 & 0 & 8.15 & 0 & 34.00 & 76 & 2.11 \\
\hline
\end{tabular}

Table 5: Distributions of Weighted Degree Centrality by field, layer 2.

\begin{tabular}{lcccccccc}
\hline & Field & $\mathrm{n}$ & min & mean & median & ninety & max & skew \\
\hline 1 & Academic & 552 & 0 & 1.29 & 0 & 2 & 128 & 13.02 \\
2 & Educational & 14 & 0 & 1.5 & 1 & 3 & 7 & 1.41 \\
3 & Bureaucratic & 313 & 0 & 1.85 & 1 & 3 & 169 & 15.43 \\
4 & Consulting & 51 & 0 & 5.92 & 0 & 3 & 156 & 5.28 \\
5 & Philantrophy & 205 & 0 & 1.07 & 0 & 3 & 55 & 12.46 \\
6 & Cultural & 29 & 0 & 0.59 & 0 & 2.2 & 3 & 1.38 \\
7 & Military & 9 & 0 & 0.78 & 1 & 1 & 1 & -1.12 \\
8 & OECD & 8 & 0 & 1.75 & 0 & 4.2 & 14 & 1.86 \\
9 & Economic & 338 & 0 & 1.46 & 0 & 3 & 119 & 13.51 \\
11 & Political & 135 & 0 & 1.22 & 0 & 2.60 & 91 & 10.72 \\
12 & Professional & 142 & 0 & 1.27 & 0.5 & 3 & 41 & 8.63 \\
\hline
\end{tabular}

Turning to the second dimension of field-crossing social capital, the investigation of powersymmetrical collaboration and the system of patronage, we focus the distribution of Eigenvector Centrality across all fields and in both network layers (tables 6 and 7). The values of Eigenvector Centrality in layer 1 are low in general. The only exceptions are the academic field and - compared to other fields - the economic.

The span of skewness in layer 1 , in turn, is extreme. On the left side of the distribution, we see values of -2.07 for the military field, -1.86 for the OECD, and -1.77 for the educational field, whereas the values are 11.36 (economic field) and 16.48 (academic field) respectively at the other extereme. These values indicate very high concentrations of field-crossing social capital of otherwise sparsely embedded actors. Thus, many actors are not able to achieve the collaborations of their collaboration partners by official means.

Similar to the first dimension of field-crossing social capital, layer 2 differs substantially from layer 1 with respect to values and distribution of Eigenvector Centrality. Regarding boundaryspanning individuals, much higher levels of Eigenvector Centrality and lower levels of skewness are observed. In this layer, the most central actor is situated in the bureaucratic 
field,followed by actors situated in the economic field, whereas the most central actors on average are affiliated with the OECD. Again, this finding is remarkable since the OECD is a single actor comprised of eight directories as compared to the 338 actors of the economic field and the 313 actors of the bureaucratic field.

If the findings from the first dimension of field-crossing social capital are included, it is made clear that the OECD and a small number of other actors have the ability to bridge the lack of official collaboration between other actors by individual collaboration. In this way, the OECD incorporated the ability to officialize collaborations established by other actors of the global policy advisor network.

Table 6: Distributions of Eigenvector Centrality by field, layer 1.

\begin{tabular}{|c|c|c|c|c|c|c|c|c|}
\hline & Field & $\mathrm{n}$ & $\min$ & mean & median & ninety & Max & skew \\
\hline 1 & Academic & 552 & 0 & $3.60 * 10^{-3}$ & $3.11 * 10^{-7}$ & $1.95 * 10^{-6}$ & 1.00 & 16.48 \\
\hline 2 & Educational & 14 & 0 & $2.70 * 10^{-7}$ & $3.11 * 10^{-7}$ & $3.11 * 10^{-7}$ & $3.64 * 10^{-7}$ & -1.77 \\
\hline 3 & Bureaucratic & 313 & 0 & $5.07 * 10^{-7}$ & $3.11 * 10^{-7}$ & $4.56 * 10^{-7}$ & $1.00 * 10^{-5}$ & 6.15 \\
\hline 4 & Consulting & 51 & 0 & $2.20 * 10^{-6}$ & $3.11 * 10^{-7}$ & $2.46 * 10^{-6}$ & $5.74 * 10^{-5}$ & 6.06 \\
\hline 5 & Philantrophy & 205 & 0 & $9.02 * 10^{-7}$ & $3.11 * 10^{-7}$ & $9.67 * 10^{-7}$ & $1.91 * 10^{-5}$ & 5.51 \\
\hline 6 & Cultural & 29 & 0 & $1.60 * 10^{-6}$ & $3.11 * 10^{-7}$ & $6.34 * 10^{-6}$ & $1.08 * 10^{-5}$ & 2.17 \\
\hline 7 & Military & 9 & 0 & $2.76 * 10^{-7}$ & $3.11 * 10^{-7}$ & $3.11 * 10^{-7}$ & $3.11 * 10^{-7}$ & -2.07 \\
\hline 8 & OECD & 8 & 0 & $2.72 * 10^{-7}$ & $3.11 * 10^{-7}$ & $3.11 * 10^{-7}$ & $3.11 * 10^{-7}$ & -1.86 \\
\hline 9 & Economic & 338 & 0 & $2.84 * 10^{-6}$ & $3.11 * 10^{-7}$ & $1.00 * 10^{-5}$ & $1.72 * 10^{-4}$ & 11.36 \\
\hline 10 & Political & 135 & 0 & $4.56 * 10^{-7}$ & $3.11 * 10^{-7}$ & $3.11 * 10^{-7}$ & $1.00 * 10^{-5}$ & 7.55 \\
\hline 11 & Professional & 142 & 0 & $7.45 * 10^{-7}$ & $3.11 * 10^{-7}$ & $1.44 * 10^{-6}$ & $1.91 * 10^{-5}$ & 6.67 \\
\hline
\end{tabular}

Table 7: Distributions of Eigenvector Centrality by field, layer 2.

\begin{tabular}{|c|c|c|c|c|c|c|c|c|}
\hline & Field & $\mathrm{n}$ & $\min$ & mean & median & ninety & $\max$ & skew \\
\hline 1 & Academic & 552 & 0 & $3.98 * 10^{-2}$ & $4.41 * 10^{-2}$ & $4.41 * 10^{-2}$ & $2.42 * 10^{-1}$ & 3.87 \\
\hline 2 & Educational & 14 & 0 & $3.61 * 10^{-2}$ & $4.41 * 10^{-2}$ & $5.82 * 10^{-2}$ & $1.17 * 10^{-1}$ & 0.95 \\
\hline 3 & Bureaucratic & 313 & 0 & $5.92 * 10^{-2}$ & $4.41 * 10^{-2}$ & 0.12 & 1.00 & 5.80 \\
\hline 4 & Consulting & 51 & 0 & $4.66 * 10^{-2}$ & $4.41 * 10^{-2}$ & $4.41 * 10^{-2}$ & $2.42 * 10^{-1}$ & 3.36 \\
\hline 5 & Philantrophy & 205 & 0 & $4.15^{*} 10^{-2}$ & $4.41 * 10^{-2}$ & $4.41 * 10^{-2}$ & $2.76 * 10^{-1}$ & 5.03 \\
\hline 6 & Cultural & 29 & $1.11 * 10^{-2}$ & $4.78 * 10^{-2}$ & $4.41 * 10^{-2}$ & $4.41 * 10^{-2}$ & $2.42 * 10^{-1}$ & 4.36 \\
\hline 7 & Military & 9 & $3.40 * 10^{-2}$ & $3.65 * 10^{-2}$ & $4.41 * 10^{-2}$ & $4.41 * 10^{-2}$ & $4.41 * 10^{-2}$ & 1.12 \\
\hline 8 & OECD & 8 & $4.41 * 10^{-2}$ & $7.09 * 10^{-2}$ & $4.41 * 10^{-2}$ & 0.11 & $2.59 * 10^{-1}$ & 1.86 \\
\hline 9 & Economic & 338 & 0 & $4.52 * 10^{-2}$ & $4.41 * 10^{-2}$ & 0.07 & $3.23 * 10^{-1}$ & 5.99 \\
\hline 10 & Political & 135 & 0 & $5.21 * 10^{-2}$ & $4.41 * 10^{-2}$ & $4.41 * 10^{-2}$ & $2.42 * 10^{-1}$ & 3.65 \\
\hline 11 & Professional & 142 & 0 & $4.83 * 10^{-2}$ & $4.41 * 10^{-2}$ & 0.06 & $2.74 * 10^{-1}$ & 3.16 \\
\hline
\end{tabular}

Overall, these findings indicate a system of patronage revolving around a limited number of boundary-spanning actors, and the central role of the OECD as a platform and its ability to draw on field-crossing social capital to establish a system of patronage with a limited number of central actors within the global policy advisor network. 
Further evidence for the system of patronage exists in the third dimension of field-crossing social capital. Measured by transitivity, this dimension provides us with information on the ability to exclude less powerful actors from forming close collaborations that span different fields. Transitivity in layer 1 indicates that only a tiny share of actors is able to form triads and even fewer have the ability to connect their collaborators with each other (see table 8). Albeit the skewness is low compared to Weighted Degree and Eigenvector Centrality, the median, 90\% percentile and maximum values hint at few actors with closed triads, and thus power-symmetrical collaborations. At the same time, there is an abundance of collaborating actors linked to a few centers of power, providing evidence for patronage.

The opposite is true for layer 2. Beginning with skewness, we see extreme values ranging between 6.73 (field of consulting) and 17.40 (bureaucratic field), with the OECD as the only exception (skewness $=1.86$ ). Even more suprising is the fact that, for a number of fields, there is not a single closed triad at all. These include the educational field, field of philanthropy, cultural field and military field. In the remaining fields, the extremely right skewed. This distribution of values indicates that, on the individual level, only a very limited number of presumably charismatic actors account for the majority of field-crossing social capital.

Finally, this interpretation is backed by network density measures. Overall, only $0.075 \%$ of all possible collaborations were realized in layer 1 and $0.018 \%$ in layer 2 . On the organizational and the individual level, these numbers provide further evidence for the system of patronage outlined above. Collaboration and taking part in the global field of power and the global policy advisor network seems only possible if an actor collaborates with the OECD and other powerful actors with abundant field-crossing social and symbolic capital.

Table 8: Distributions of Transitivity by field, layer1.

\begin{tabular}{lcccccccc} 
& Field & $\mathrm{n}$ & min & mean & median ninety max skew \\
\hline 1 & Academic & 552 & 0 & 0.26 & 0 & 1 & 1 & 1.11 \\
2 & Educational & 14 & 0 & 0.14 & 0 & 0.70 & 1 & 1.83 \\
3 & Bureaucratic & 313 & 0 & 0.13 & 0 & 1 & 1 & 2.15 \\
4 & Consulting & 51 & 0 & 0.19 & 0 & 1 & 1 & 1.61 \\
5 & Philantrophy & 205 & 0 & 0.24 & 0 & 1 & 1 & 1.24 \\
6 & Cultural & 29 & 0 & 0.35 & 0 & 1 & 1 & 0.62 \\
7 & Military & 9 & 0 & 0.11 & 0 & 0.20 & 1 & 2.07 \\
8 & OECD & 8 & 0 & 0.02 & 0 & 0.06 & 0.2 & 1.86 \\
9 & Economic & 338 & 0 & 0.44 & 0 & 1 & 1 & 0.25 \\
11 & Political & 135 & 0 & 0.07 & 0 & 0 & 1 & 3.22 \\
12 & Professional & 142 & 0 & 0.24 & 0 & 1 & 1 & 1.22 \\
\hline
\end{tabular}


Table 9: Distributions of Transitivity by field, layer 2.

\begin{tabular}{lcccccccc}
\hline & Field & $\mathrm{n}$ & min & mean & median ninety & max & skew \\
\hline 1 & Academic & 552 & 0 & $7.98 * 10^{-3}$ & 0 & 0 & 1 & 11.09 \\
2 & Educational & 14 & 0 & 0 & 0 & 0 & 0 & - \\
3 & Bureaucratic & 313 & 0 & $6.21 * 10^{-05}$ & 0 & 0 & 0.02 & 17.40 \\
4 & Consulting & 51 & 0 & $6.49 * 10^{-06}$ & 0 & 0 & $3.31 * 10^{-4}$ & 6.73 \\
5 & Philantrophy & 205 & 0 & 0 & 0 & 0 & 0 & - \\
6 & Cultural & 29 & 0 & 0 & 0 & 0 & 0 & - \\
7 & Military & 9 & 0 & 0 & 0 & 0 & 0 & - \\
8 & OECD & 8 & 0 & 0.02 & 0 & 0.042 & 0.14 & 1.86 \\
9 & Economic & 338 & 0 & $4.15^{*} 10^{-3}$ & 0 & 0 & 1 & 16.02 \\
10 & Political & 135 & 0 & $7.407 * 10^{-3}$ & 0 & 0 & 1 & 11.36 \\
11 & Professional & 142 & 0 & $1.76 * 10^{-4}$ & 0 & 0 & 0.03 & 11.67 \\
\hline
\end{tabular}

\section{Discussion and conclusion}

The article at hand investigates the global policy advisor network and maps the collaborations between the OECD and other members of the global policy advisor network and the edubusiness. These collaborations span between different types of oganizations and include different types of experts and are necessary to steer educational reforms. These experts revolve around the OECD and the PISA tests as well as among a limited number of other actors and include both official and individual collaboration that get officialized by the partaking organizations. To conceptualize the different forms of collaborations and coordination among experts and organizations, we integrated concepts of Habitus-Field Theory and Social Network Theory and introduced the concepts of boundary-spanning actors and field-crossing social capital. We introduced three dimensions of field-crossing social capital available to boundary-spanning actors.

To map the global policy advisor network and to apply our theoretical concepts, we conducted an iterative web search to establish a two-layer network based on official collaboration and personal collaborations as outlined above. In total, we collected 6866 collaborations of 1796 actors in the two layers. In this way, we found that PISA is not a single cause of change in education and educational governance, but is rather part of a complex global movement that takes education under control with the help of statistical figures. Accordingly, in addition to PISA, it is also reflected in other performance comparisons at the international level and in the subjugation of education to increasingly comprehensive monitoring at the national level (cf. Kamens and McNeely 2010). 
Since the global policy advisor network draws on different types of expertise tied to different sectors within the global field of power, the OECD and its partners situated in different fields establish a network of a limited number of power-symmetrical collaborations and, at the same time, a system of patronage. These collaborations reveal firstly a central role of the academic and economic fields in the case of officialized collaborations and the role of the OECD and actors stemming from the cultural field in the case of individual collaborations. Secondly, the ability to knit both levels of field-crossing collaborations - and thus field-crossing social capital - of other actors of the global policy advisor network highlights the role of the OECD as a platform to establish a shared doxa, nomos, illusio andthe belief on how education reform and educational testing should be conducted and by whom (libido).

This figuration helps to mobilize expertise and accumulate expertise by addressing and changing the habitus of actors tied to different positions in the social space. At the same time, this figuration prevents other actors from becoming boundary-spanning and accumulating field-crossing social capital. Thus, the figuration of a closed circle of equally powerful actors along with a patronage relationship between this circle and a great variety of less powerful actors forms the very basis on which PISA is not simply a proliferation of data informing national policy about the performance of 15-year old students and some subgroups of them in various countries and about a variety of factors associated with performance in the test. It is rather a benchmark and information basis, which exerts constraints on national policies to meet the standards applied by the test. On a more theoretical note, our findings highlight the importance to relate different forms of symbolic capital to shape the autonomy of (nationally embedded) fields and to have an impact on the interpretation of "good" education, as Schmitz, Witte and Gengnagel (2017) and Krause (2018) described.

Contrary to official language, national governments are not completely free in deriving conclusions from the test (Addey 2017; Hartong 2018a; Niemann and Martens 2018; Rautalin, Alasuutari, and Vento 2019; Wilkins et al. 2019). In order to maintain legitimacy, they are forced to initiate policies, which are considered effective with regard to meeting PISA standards. The arena within which legitimacy is constructed is no longer simply national democratic decision-making, lobbying by teacher associations and media coverage, but a global field of power that has emerged around the OECD and comprises a network of boundary-spanning organizational and individual actors with high levels of expertise and field-crossing social capital. This accounts for the concentration of power in the inner circle 
of this network and allows for forming worldwide binding concepts of education and education governance.

This is the powerbase of what - in the perspective of sociological neoinstitutionalism - is the role of "cultural others" who represent binding standards for constructing national institutions ( Meyer et al. 1997). In as much as the institutions meet these standards they are considered legitimate. In our case, we can say that the role of the inner circle of the global policy advisor network as "cultural others" implies that no national school system can claim legitimacy which is underperforming in the PISA test in comparison to countries regarded as competitors on the same level. For making the PISA standards set by the inner circle of the global advisor network binding for any national education policy, there must be a bridge from this inner circle to the national arenas of policy-making. This is precisely the role of the patronage system that involves a large number of actors, which are part of the global network but in the subordinate position of passive recipients of standards, data and best practice recommendations. Without this bridging function of the patronage system, national education policy would remain unimpressed by global standards set by tests like PISA.

Our study proves that PISA exactly represents such a case of replacing separate national policy-making by a type of multilevel governance with a considerable shift of power from the national to the global level by installing an inner circle of equally powerful boundaryspanning actors possessing field-crossing social capital and whether there is a patronage system serving as bridge for translating global standards into national policies. It thus also proves our point that every nation state is located within a global field of power that is colonized by transnational networks such as the global policy advisor network. In this respect, our study contributes to the literature on this type of educational governance (Ball and Junemann 2012; Ball 2016; Lewis and Lingard 2015; Sellar 2015; Hartong 2018b, 32-39).

A further contribution of our study concerns the literature dealing with the increasing selfgovernance of international organizations, following their own institutional, bureaucratic logic, independent of the formal governance by its member states (Barnett and Finnemore 2004). Additionally, this literature also addresses the widespread lobbying emerging around international organizations so that formal control by member states is superimposed by informal influence of powerful lobby groups. The result is a conglomerate of actors involved in an intransparent transnational decision-making process, which is difficult to disentangle 
and to subject to democratic control. We may coin this type of governance as multilevel governance by patronage.

What makes the OECD and its educational benchmarking with PISA unique, is that it goes beyond the narratives of self-governing bureaucracy and capture by lobby groups. It is the establishment of a network of organizational and individual actors with an inner circle of equally powerful actors defining the standards of education at school and an additional patronage system serving as a bridge for imposing trannational education standards as binding yardsticks on national education policy. Transnational bodies and the nation states must be interpreted as actors in the global field of power with the ability to accumulate field-crossing social capital, to harmonize different forms of habitus, illusio, doxa, nomoi and libidos and to exert influence by coordination of different forms of symbolic capital on many levels at the same time. By applying our framework, we may uncover hidden mechanisms of legitimation, lobbying and even corruption beyond the global policy advisor network revolving around OECD and PISA. 


\section{Literature}

Addey, Camilla. 2017. “Golden Relics \& Historical Standards: How the OECD Is Expanding Global Education Governance through PISA for Development.” Critical Studies in Education 58 (3): 311-325.

Addey, Camilla, and Sam Sellar. 2018. "Why Do Countries Participate in PISA? Understanding the Role of International Large-Scale Assessments in Global Education Policy.” Global Education Policy and International Development: New Agendas, Issues and Policies, 97.

Aldrich, Howard, and Diane Herker. 1977. "Boundary Spanning Roles and Organization Structure.” Academy of Management Review 2 (2): 217-230.

Ball, Stephen J. 2012. Global Education Inc: New Policy Networks and the Neo-Liberal Imaginary. Routledge.

Ball, Stephen J. 2016. "Following Policy: Networks, Network Ethnography and Education Policy Mobilities.” Journal of Education Policy 31 (5): 549-566.

Ball, Stephen J, and Carolina Junemann. 2012. Networks, New Governance and Education. Policy Press.

Barabási, A. L, H Jeong, Z Néda, E Ravasz, A Schubert, and T Vicsek. 2002. "Evolution of the Social Network of Scientific Collaborations.” Physica A: Statistical Mechanics and Its Applications 311 (3): 590-614. doi:10.1016/S0378-4371(02)00736-7.

Barnett, Michael, and Martha Finnemore. 2004. Rules for the World: International Organizations in Global Politics. Cornell University Press.

Borgatti, Stephen P, and Martin G Everett. 2006. "A Graph-Theoretic Perspective on Centrality.” Social Networks 28 (4): 466-484.

Bourdieu, Pierre. 1985. "The Social Space and the Genesis of Groups.” Theory and Society 14 (6): 723-744. doi:10.2307/657373.

Bourdieu, Pierre. 1986. "The Force of Law: Toward a Sociology of the Juridical Field.” Hastings LJ 38: 805.

Bourdieu, Pierre. 1989. "Social Space and Symbolic Power.” Sociological Theory 7 (1): 14. doi:10.2307/202060.

Bourdieu, Pierre. 1996. The State Nobility: Elite Schools in the Field of Power. Cambridge: Polity Press.

Bourdieu, Pierre. 2000. Pascalian Meditations. Stanford, Calif: Stanford University Press.

Bourdieu, Pierre, Loic J. D. Wacquant, and Samar Farage. 1994. "Rethinking the State: Genesis and Structure of the Bureaucratic Field.” Sociological Theory 12 (1): 1-18. doi:10.2307/202032.

Bourdieu, Pierre, and Kathe Robinson. 1985. "Delegation and Political Fetishism.” Thesis Eleven 10 (1): 56-70.

Bourdieu, Pierre, and Loïc J. D. Wacquant. 1992. An Invitation to Reflexive Sociology. New. Chicago: University of Chicago Press.

Burt, Ronald S. 1980. "Cooptive Corporate Actor Networks: A Reconsideration of Interlocking Directorates Involving American Manufacturing.” Administrative Science Quarterly 25 (4): 557-582. doi:10.2307/2392281.

Burt, Ronald S. 2000. "The Network Structure Of Social Capital." Research in Organizational Behavior 22: 345-423. doi:10.1016/S0191-3085(00)22009-1.

Engel, Laura C., and Matthew O. Frizzell. 2015. "Competitive Comparison and PISA Bragging Rights: Sub-National Uses of the OECD’s PISA in Canada and the USA.” Discourse: Studies in the Cultural Politics of Education 36 (5): 665-682. doi:10.1080/01596306.2015.1017446. 
Freeman, Linton C. 1977. "A Set of Measures of Centrality Based on Betweenness." Sociometry 40 (1): 35. doi:10.2307/3033543.

Fuhse, Jan A. 2009. “The Meaning Structure of Social Networks.” Sociological Theory 27 (1): 51-73. doi:10.2307/40376109.

Grow, André, Andreas Flache, and Rafael Wittek. 2017. "Global Diversity and Local Consensus in Status Beliefs: The Role of Network Clustering and Resistance to Belief Change.” Sociological Science 4: 611-640. doi:10.15195/v4.a25.

Hartong, Sigrid. 2016. "Between Assessments, Digital Technologies and Big Data: The Growing Influence of 'Hidden'Data Mediators in Education.” European Educational Research Journal 15 (5): 523-536.

Hartong, Sigrid. 2018a. "Towards a Topological Re-Assemblage of Education Policy? Observing the Implementation of Performance Data Infrastructures and 'Centers of Calculation'in Germany.” Globalisation, Societies and Education 16 (1): 134-150.

Hartong, Sigrid. 2018b. Standardbasierte Bildungsreformen in Den USA: Vergessene Ursprünge Und Aktuelle Transformationen. Beltz Juventa.

Head, Brian W. 2016. “Toward More 'Evidence-Informed' Policy Making?” Public Administration Review 76 (3): 472-484. doi:10.1111/puar.12475.

Hogan, Anna. 2015. "Boundary Spanners, Network Capital and the Rise of Edu-Businesses: The Case of News Corporation and Its Emerging Education Agenda." Critical Studies in Education 56 (3): 301-314. doi:10.1080/17508487.2014.966126.

Hogan, Anna. 2016. "NAPLAN and the Role of Edu-Business: New Governance, New Privatisations and New Partnerships in Australian Education Policy.” The Australian Educational Researcher 43 (1): 93-110. doi:10.1007/s13384-014-0162-z.

Hogan, Anna, Sam Sellar, and Bob Lingard. 2015. "Network Restructuring of Global EduBusiness.” W. Au, \& JJ Ferrare, Mapping Corporate Education Reform. Power and Policy Networks in the Neoliberal State, 43-64.

Kamens, David H, and Connie L McNeely. 2010. "Globalization and the Growth of International Educational Testing and National Assessment.” Comparative Education Review 54 (1): 5-25.

Kim, Jung Yeol, and K.-I. Goh. 2013. "Coevolution and Correlated Multiplexity in Multiplex Networks.” Physical Review Letters 111 (5). doi:10.1103/PhysRevLett.111.058702.

Kossinets, Gueorgi, and Duncan J Watts. 2006. "Empirical Analysis of an Evolving Social Network.” Science 311 (5757): 88-90.

Krause, Monika. 2018. “How Fields Vary.” The British Journal of Sociology 69 (1): 3-22.

Lazega, Emmanuel, and Philippa E Pattison. 1999. "Multiplexity, Generalized Exchange and Cooperation in Organizations: A Case Study.” Social Networks 21 (1): 67-90. doi:10.1016/S0378-8733(99)00002-7.

Leuze, Kathrin, Kerstin Martens, and Alessandra Rusconi. 2007. New Arenas of Education Governance-the Impact of International Organizations and Markets on Education Policy Making.

Lewis, Steven. 2017. "Policy, Philanthropy and Profit: The OECD's PISA for Schools and New Modes of Heterarchical Educational Governance.” Comparative Education 53 (4): 518-537.

Lewis, Steven, and Ian Hardy. 2015. "Funding, Reputation and Targets: The Discursive Logics of High-Stakes Testing.” Cambridge Journal of Education 45 (2): 245-264. doi:10.1080/0305764X.2014.936826.

Lewis, Steven, and Anna Hogan. 2019. "Reform First and Ask Questions Later? The Implications of (Fast) Schooling Policy and 'Silver Bullet'Solutions.” Critical Studies in Education 60 (1): 1-18. 
Lewis, Steven, and Bob Lingard. 2015. "The Multiple Effects of International Large-Scale Assessment on Education Policy and Research.” Discourse: Studies in the Cultural Politics of Education 36 (5): 621-637. doi:10.1080/01596306.2015.1039765.

Lin, Nan. 2017. "Building a Network Theory of Social Capital.” In Social Capital, 3-28. Routledge.

Lingard, Bob. 2013. "The Impact of Research on Education Policy in an Era of EvidenceBased Policy.” Critical Studies in Education 54 (2): 113-131.

Lingard, Bob, Wayne Martino, and Goli Rezai-Rashti. 2013. “Testing Regimes, Accountabilities and Education Policy: Commensurate Global and National Developments."

Liu, Yike, Tara Safavi, Neil Shah, and Danai Koutra. 2018. "Reducing Large Graphs to Small Supergraphs: A Unified Approach.” Social Network Analysis and Mining 8 (1): 17.

Mahon, Rianne. 2010. "After Neo-Liberalism? The OECD, the World Bank and the Child.” Global Social Policy 10 (2): 172-192.

Meyer, Heinz-Dieter. 2014. "The OECD as Pivot of the Emerging Global Educational Accountability Regime: How Accountable Are the Accountants.” Teachers College Record 116 (9): 1-20.

Meyer, John W, John Boli, George M Thomas, and Francisco O Ramirez. 1997. "World Society and the Nation-State.” American Journal of Sociology 103 (1): 144-181.

Newman, M. E. J. 2004. "Coauthorship Networks and Patterns of Scientific Collaboration.” Proceedings of the National Academy of Sciences 101 (Supplement 1): 5200-5205. doi:10.1073/pnas.0307545100.

Newman, M. E. J. 2006. "Modularity and Community Structure in Networks.” Proceedings of the National Academy of Sciences of the United States of America 103 (23): 85778582. doi:10.1073/pnas.0601602103.

Niemann, Dennis, and Kerstin Martens. 2018. "Soft Governance by Hard Fact? The OECD as a Knowledge Broker in Education Policy.” Global Social Policy 18 (3): 267-283.

Opsahl, Tore, Filip Agneessens, and John Skvoretz. 2010. "Node Centrality in Weighted Networks: Generalizing Degree and Shortest Paths.” Social Networks 32 (3): 245251.

Pachucki, Mark A, and Ronald L Breiger. 2010. "Cultural Holes: Beyond Relationality in Social Networks and Culture.” Annual Review of Sociology 36.

Padgett, John F., and Christopher K. Ansell. 1993. "Robust Action and the Rise of the Medici, 1400-1434." American Journal of Sociology 98 (6): 1259-1319. doi:10.1086/230190.

Padgett, John F, and Paul D McLean. 2006. "Organizational Invention and Elite Transformation: The Birth of Partnership Systems in Renaissance Florence.” American Journal of Sociology 111 (5): 1463-1568.

Pusser, Brian, Sheila Slaughter, and Scott L. Thomas. 2006. "Playing the Board Game: An Empirical Analysis of University Trustee and Corporate Board Interlocks." The Journal of Higher Education 77 (5): 747-775.

Rautalin, Marjaana, Pertti Alasuutari, and Eetu Vento. 2019. “Globalisation of Education Policies: Does PISA Have an Effect?” Journal of Education Policy 34 (4): 500-522.

Schinkel, Willem, and Mirko Noordegraaf. 2011. "Professionalism as Symbolic Capital: Materials for a Bourdieusian Theory of Professionalism.” Comparative Sociology 10 (1): 67-96.

Schmidt-Wellenburg, Christian. 2017. "Europeanisation, Stateness, and Professions: What Role Do Economic Expertise and Economic Experts Play in European Political 
Integration?” European Journal of Cultural and Political Sociology 4 (4): 430-456. doi:10.1080/23254823.2017.1335222.

Schmitz, Andreas, Daniel Witte, and Vincent Gengnagel. 2017. "Pluralizing Field Analysis: Toward a Relational Understanding of the Field of Power." Social Science Information 56 (1): 49-73. doi:10.1177/0539018416675071.

Sellar, Sam. 2015. “A Feel for Numbers: Affect, Data and Education Policy.” Critical Studies in Education 56 (1): 131-146.

Sellar, Sam, and Bob Lingard. 2013. "PISA and the Expanding Role of the OECD in Global Educational Governance." PISA, Power, and Policy: The Emergence of Global Educational Governance, 185-206.

Serre, Delphine, and Anne-Catherine Wagner. 2015. "For a Relational Approach to Cultural Capital: A Concept Tested by Changes in the French Social Space.” The Sociological Review 63 (2): 433-450. doi:10.1111/1467-954X.12292.

Traxl, Dominik, Niklas Boers, and Jürgen Kurths. 2016. "Deep Graphs-A General Framework to Represent and Analyze Heterogeneous Complex Systems across Scales.” Chaos: An Interdisciplinary Journal of Nonlinear Science 26 (6): 065303.

Watts, Duncan J. 1999. "Networks, Dynamics, and the Small-World Phenomenon." American Journal of Sociology 105 (2): 493-527.

White, Douglas R., Jason Owen-Smith, James Moody, and Walter W. Powell. 2004. "Networks, Fields and Organizations: Micro-Dynamics, Scale and Cohesive Embeddings.” Computational \& Mathematical Organization Theory 10 (1): 95-117. doi:10.1023/B:CMOT.0000032581.34436.7b.

Wilkins, Andrew, Jordi Collet-Sabé, Brad Gobby, and Judith Hangartner. 2019. “Translations of New Public Management: A Decentred Approach to School Governance in Four OECD Countries." Globalisation, Societies and Education, 1-14.

Williams, Paul. 2011. "The Life and Times of the Boundary Spanner.” Journal of Integrated Care.

Williams, Paul. 2013. “We Are All Boundary Spanners Now?” International Journal of Public Sector Management. 


\section{Appendix A - Definition of fields and rationale for assigning actors to different fields}

OECD: the OECD is not a field in its own right. Nonetheless, we decided to include the OECD into our analysis as a separate field, since it is the organizer of the PISA-test, which is pivotal for the global Edu-business. Furthermore, the OECD is a boundary-spanning organization within the global field of power, investing economic, cultural and social capital in order to gain different symbolic capitals (administrative capital, economic capital, academic capital, consulting capital). The OECD does so in order to shape the very idea of how education is defined, how to govern and test the advancement of education on the national level and how to compare education, educational achievement and success of educational reforms properly. The doxa of the OECD is best described as improving the quality of life - interlinked with economic growth - by steering educational fields from a distance while improving the human capital of nation states and on the global level. At the same time, the OECD and its expert panels serve as a meeting ground for (educational) experts related to different fields, thus providing the social capital necessary for global education reforms. We therefore suppose that the OECD's main symbolic capital is a mixture of social capital and the ability to unify different forms of expertise and symbolic capital into a common framework. Organizational units of the OECD are regarded as being part of the OECD "field", as well as individuals who are mainly affiliated with the OECD directorate or other organizational units.

Academic field: The academic field is defined as an area of the social space concerned with the systematic discovery and investigation of phenomena on the theoretical, paradigmatic and empirical levels. The illusio and doxa of the academic field are associated with the conviction that it is important to create knowledge for its own sake and be disinterested in political or economic issues. Actors located in the academic field are either universities or research institutes. These actors strive to accumulate academic capital that is acknowledged by peers in terms of publications, citations, scientific prizes, amassing positions in scholarly associations, being experts and reviewers. In this way, they intend to shape the academic field and define the distinction between relevant and irrelevant research for their own discipline, but also for actors located in different fields such as politicians, bureaucrats or economists.

Professional field: The professional field is closely related to the academic field and comprises of professional societies and actors concerned with the issue of how to represent their own discipline within the academic field, the field of power and in regard to interests of actors located in different fields (e.g. administrative bodies). The professional field is therefore seen as interstitial between the academic field, the bureaucratic field, the political field and the economic field. Since it covers actors with affiliations in the academic field and with representative functions, the associated symbolic capital is comprised of academic capital and a sort of political capital, since actors in the professional field are delegated and legitimated to speak for the academic field. The illusio and doxa are associated with how to represent academia and how the academic field is legitimately linked to and addressed by actors of different fields. Actors located in this field are either professional societies (e.g. the American Sociological Association) or actors working mainly for such societies (e.g. the president of the American Statistical Association) or unions (e.g. teacher unions). 
Economic field: The economic field is defined as an area of the social space concerned with the production of material goods or intellectual property. The main interest of the actors located in this societal domain is the accumulation of wealth in the form of money, stock market shares, revenues, or monies. The doxa is best described as "business is business", comprising of ideas of how to generate wealth and revenues in the best possible manner, while the symbolic capital associated is economic capital and the (positive) change thereof in a given amount of time.

Field of Philanthropy: The field of philanthropy is an area within the social space including actors aiming to do something "good" for others such as improving the quality of life, addressing environmental issues, or supporting progress in medical research. The main issue in this field is how to improve. for instance, the quality of life in an appropriate way. To do so, actors in this field - such as the Bill and Melinda Gates foundation - convert huge sums of economic capital into academic capital, social capital (e.g. provide platforms for exchange) and aim to use the cultural capital created for local and global projects, but also for consulting and steering activities on the governmental and political levels. Therefore, the illusio and doxa are concerned with the question of how to do "good" in the right way, how to generate evidence proving that something good was done and how to measure the progress correctly (e.g. reduction of poverty or illiteracy). Besides philanthropies on the organizational level, we count experts and administrators of philanthropies as actors situated in the field of philanthropy.

Field of Consulting: The field of consulting is a field of different experts and their expertise, e.g. educational expertise, economic expertise. Actors located in this field aim to provide the legitimation, and hence the cultural and symbolic capital necessary for customers in other fields to implement novel strategies, ideas and aims, which have originally not been compatible with the illusios, nomoi and doxa of these fields. Therefore, their symbolic capital might be called heteronomic capital, that is the power to legitimize strategies and modes of capital accumulation of actors in other fields. Therefore, actors in this field are supporting players for actors in other fields who aim to shape the illusio of the fields from within but lack the acknowledgment within their own fields or by others within the field of power. Actors located in this field are either consulting agencies, e.g. Boston Consulting, McKinsey, or think tanks such as the Hoover Institution. We assign individuals to the field of consulting, if they are mainly associated with the two types of actors outlined above and take part in the global Edu-Business either as experts or in the administrative leadership.

Bureaucratic field: The bureaucratic field consists of administrative units such as ministries. It covers the sector of the social space dealing with the idea of statehood and how to govern a state properly. The symbolic capital associated with this field is statist capital, "which enables the state to exercise power over different particular forms of capital" (Bourdieu, Loic J. D. Wacquant, and Farage 1994, 4) and therefore the exchange rates between different forms of capital. Furthermore, actors in the bureaucratic field - such as ministries - accumulate information capital. Information capital is defined as a special form of cultural capital useful to govern the citizens and to provide evidence and advice for steering reforms. Actors associated with this field are either linked to ministries or administrative bodies such as expert commissions.

Political Field: The political field is defined as the section of the social space associated with the representation of different societal groups and classes. Actors located in this field are delegated to represent not only the different groups but also their interests as perceived by the political actors. The illusio and doxa are related to the aim to impose the interests of different 
societal groups on other actors in the political field. Furthermore, the illusio and doxa are intended to relate the aims of the represented societal groups to generalized agendas linked to societal goals, reform projects as well as adaptations towards domestic affairs, foreign affairs or changing economic, demographic and educational conditions of the citizenship. Actors assigned to the political field are directly associated with governments such as government officials, ambassadors, ministers, secretaries or politicians representing the opposition of the respective countries.

Military Field: The military field is defined as a section of the social space associated with national defense, the forces and the capacity to exert dominance and violence over nation states and safeguard citizens from threats such as terrorism. The illusio and doxa of the field are best described by the words of Publius Flavius Vegetius Renatus "Therefore he who desires peace, let him prepare for war", which includes preparing a state's workforce and the educational field in such a manner as to overpower other states. In this sense, actors located in this field take interest in educational research and studies in order to act in accordance with the illusio and doxa outlined above. The symbolic capital of the military field therefore comprises of the possibility to exert violence and subdue other states and threats. Actors associated with this field are military units (e.g. the U.S. Air Force) or representatives of the military leadership (e.g. generals).

Cultural Field: The cultural field is defined as the part of the social space where the definition of legitimate culture and cultural products is contested. This field includes, for instance, the schooling system, galleries, the media, publishers, art galleries, operas, or theaters. Actors in this field aim to legitimately define what counts as valuable art, cultural heritage, is and - on the global level - which "cultural” products, valuations and ways of consumption (e.g. high-brow art or popular art) are legit and worth striving for. The cultural field is affected by the dualism between liberal arts and knowledge, education and cultural consumption to increase productivity and human capital, and thus defines whether "culture" is interpreted as a value in itself or a means to augment economic growth and economic productivity.

Bourdieu, Pierre, Loic J. D. Wacquant, and Samar Farage. 1994. "Rethinking the State: Genesis and Structure of the Bureaucratic Field." Sociological Theory 12 (1): 1-18. doi:10.2307/202032. 